\title{
SOFT POWER, O BRILHO DA ESPADA: O BRASIL E A ORDEM INTERNACIONAL PÓS 11 DE SETEMBRO
}

\author{
Roberto Goulart Menezes ${ }^{1}$
}

\begin{abstract}
Resumo
0 objetivo deste artigo é examinar em que medida os eventos de 11 de setembro de 2001 contribuíram para a revisão da inserção internacional do Brasil e de como estes influíram na elaboração de uma nova estratégia no governo Lula da Silva (20032010). Entre as principais mudanças na agenda externa do País figuram a derrocada das negociações da ALCA, a busca de uma inserção soberana e o fortalecimento de uma ordem multipolar. Para isso, os eventos de 11 de setembro são discutidos à luz do conceito braudeliano de longa duração, que separa os acontecimentos de curta duração (os episódios) daqueles que ressoam e acabam por mudar os rumos da história dos povos e das nações.
\end{abstract}

Palavras-chave: Ordem internacional. Governo Lula. Estados Unidos. Longa duração.

\section{SOFT POWER, THE BRIGHTNESS OF THE SWORD BraZIL AND THE INTERNATIONAL ORDER AFTER SEPTEMBER 11}

\begin{abstract}
This paper aims at examining how the events of September 11, 2001 have contributed to the review of the international insertion of Brazil and how those events influenced in the elaboration of a new strategy during the presidential years of Lula da Silva (20032010). Among the main changes of the country's external agenda figure the failing of the negotiation of ALCA, (FTAA - Free Trade Area of the Americas) the searching for
\end{abstract}

${ }^{1}$ Professor-adjunto de Política Internacional na Universidade de Brasília, Brasil. rgmenezes@unb.br 
a sovereign insertion and the fortification of a multipolar order. Therefore, the events of September 11 are discussed under Braudel's conception of long duration that set apart happenings of short duration (the episodes) from those that resound and start changing the ways of people's history and nations.

Keywords: International order. Lula's government. The United States. Long duration.

\title{
INTRODUÇÃO
}

\author{
Todos nós, inevitavelmente, escrevemos a história de nosso \\ próprio tempo quando olhamos o passado e, em alguma medida, \\ empreendemos as batalhas de hoje no figurino do período. Mas aqueles \\ que escrevem somente a bistória de seu próprio tempo não podem \\ entender o passado e aquilo que veio dele. Podem até mesmo falsificar \\ o passado e o presente, mesmo sem intenção de o fazer. \\ Eric Hobsbawm. Ecos da Marselhesa, 1990.
}

$\mathrm{E}$

m Ecos da Marselhesa (HOBSBAWM, 1990), coletânea de ensaios sobre os 200 anos da Revolução Francesa, Hobsbawm analisa a herança e os "ecos" da revolução burguesa que ressoam ainda hoje no pensamento, na vida política, cultural e intelectual do Ocidente. Entre os legados da França revolucionária de 1789, o eminente historiador destaca as transformações no trato da coisa pública, o fim dos privilégios de sangue e a instituição de direitos de cidadania, a luta por direitos sociais, políticos e econômicos. É difícil conceber a história Ocidental sem esse evento histórico de longa duração. Na formulação de Fernand Braudel (1972, p. 14) "o tempo breve é a mais caprichosa, a mais enganadora das durações." Para ele, a análise dos acontecimentos requer uma separação dos acontecimentos de curta duração (os episódios) dos eventos históricos que transformam os rumos da história e ressoam profundamente nos povos e nas nações.

As comemorações do bicentenário da queda da Bastilha em 1989 foram marcadas pelas profundas transformações geopolíticas na Europa e no mundo. Os regimes de partido único da Europa do leste - o "socialismo real" - foram postos abaixo pelas populações e o muro de Berlim, símbolo maior da guerra fria, derrubado. Os regimes implantados à força pelos soviéticos após a Segunda 
Guerra Mundial foram derrubados um a um, espalharam a "revolução de veludo" e sacudiram toda a região. No fim de 1991, a própria União Soviética se dissolveu e junto com ela a ordem da guerra fria, dando início a uma transição sistêmica nas relações internacionais (CRUZ, 2007). Os efeitos e o alcance das mudanças geopolíticas inaugurados com a queda do muro inscrevem-se na noção de longa duração braudeliana.

Em que medida o conceito de longa duração nos ajuda a pensar os atentados de 11 de setembro? No calor da hora, as leituras acerca dos seus desdobramentos na ordem internacional foram marcadas por análises de certo modo até exageradas. No geral, elas acabaram por superestimar este acontecimento sobre os rumos da ordem internacional. Chegou-se até mesmo se falar em uma possível Terceira Guerra Mundial.

0 historiador Timothy Garton Ash, que vivenciou e escreveu sobre as transformações geopolíticas na Europa do Leste em 1989, em breve artigo redigido poucos dias após os atentados de 11 de setembro, questionava:

Que tipo de evento global isso será? Será como o assassinato de Kennedy - chocante, inesquecível, mas em última análise de pouca importância para o curso da história? Ou será mais parecido com a queda do muro, um acontecimento que muda de fato o curso da história, com consequências que perduram por muitas décadas e em todos os continentes? (ASH, 2001).

Ash conclui que os ataques terroristas perpetrados contra alvos no território dos Estados Unidos seriam do segundo tipo. Sem dúvida alguma eles compõem o rol dos principais acontecimentos das relações internacionais contemporâneas. Porém, passados dez anos, a importância e 0 alcance dos atentados parecem não ter conduzido a mudanças estruturais na ordem internacional na escala prognosticada por muitos analistas à época.

0 objetivo deste artigo é examinar em que medida os eventos de 11/09 contribuíram para a revisão da inserção internacional do Brasil na ordem internacional contemporânea, em especial na gestão Lula da Silva (2003-2010). 0 trabalho está organizado da seguinte forma: além dessa introdução, o artigo apresenta um breve histórico da política internacional da era Bush (2000-2008); em seguida, caracteriza o Brasil e o sistema internacional no pós 11/09; analisa as relações do governo Lula e da era Bush e, por último, apresenta as considerações finais. 


\section{A era Bush (2000-2008): Unilateralismo E PODER BRUTO}

As gestões de George Walker Bush (2000-2008) operaram uma reformulação ultraconservadora na política externa dos Estados Unidos. Essa tendência se acentuou mais ainda após os atentados perpetrados contra as torres do World Trade Center (Nova Iorque) e ao Pentágono (Washington), em 11 de setembro de 2001, trazendo novas incertezas e impasses para o ordenamento internacional. 0 traço principal deste novo período da política externa norte-americana foi 0 unilateralismo e norteou a estratégia de segurança nacional dos Estados Unidos (setembro de 2002), denominada Doutrina Bush. Balizada no mais puro realismo político, ela recolocou a guerra em posição de destaque, trazendo ainda mais incógnitas para a ordem internacional com o princípio das guerras preventivas (BERNAL-MEZA, 2005).

A Doutrina Bush teve como estratégia maior afirmar a supremacia do poderio dos Estados Unidos no mundo e impedir a ascensão de possíveis potências que desafiassem a sua liderança. Ela consubstanciava "um projeto explícito de poder global, unipolar e quase-imperial” (FIORI, 2007, p. 9). A nova estratégia de segurança nacional transformava os demais Estados-nação em aliados ou inimigos na cruzada ao terrorismo e fez do Iraque sua primeira vítima. A deflagração da guerra em 2003, sem o aval do Conselho de Segurança (ONU), teve como objetivo central a demonstração de força internacional frente a um país derrotado, bem como exercer controle sobre as ricas jazidas petrolíferas do Iraque (HOBSBAWM, 2003). A nova agenda de Washington, ao canalizar seus esforços para o campo da segurança e defesa, pôs no limbo a cooperação internacional, o desenvolvimento, o meio ambiente, entre outros temas do multilateralismo.

0 discurso neoconservador da administração de G. Bush Jr. guardou estreita relação com o período Reagan (1980-1988) e suas semelhanças não são desprezíveis, a começar pelo ardor com que ambos defenderam o livre mercado e suas ações unilaterais perante o mundo. 0 "eixo do mal", no vocabulário de Bush, empregado para se referir aos regimes e governos hostis da política externa dos Estados Unidos, alude ao de "império do mal" que Reagan empregava à União Soviética. A tônica da estratégia neoconservadora do governo Bush Jr. buscou impor uma hegemonia global sem contestações. Os Estados Unidos, detentores de um poderio militar, tecnológico, cultural, econômico e político jamais desfrutado por 
nenhuma outra grande potência em toda a história da humanidade, ensaiaram a estratégia de um novo imperialismo.

Mostras do unilateralismo da política externa de Bush já haviam sido dadas, mesmo antes dos atentados de 11/09. Em março de 2001 o próprio presidente anunciou publicamente a rejeição dos compromissos com o Protocolo de Kyoto em nome da competitividade da economia norte-americana. A gestão Bush Jr. também vetou o Tribunal Penal Internacional Permanente, a Convenção sobre Armas Biológicas e o Tratado para banir as minas terrestres, entre outros compromissos multilaterais. Além de tentar extrair das organizações internacionais, como a Organização das Nações Unidas (ONU), o endosso a suas medidas unilaterais. A derrubada violenta do regime iraquiano de Saddam Hussein (2003), sob o álibi de que o Iraque possuía armas de destruição em massa e mantinha estreitas relações com organizações terroristas, não convenceu a opinião pública internacional nem a maioria dos governos.

Assim, o neoconservadorismo do governo Bush Jr. se acentuou ainda mais com os atentados de 2001 (AYERBE, 2006). Para Martins (2003), a plataforma vitoriosa nas eleições norte-americanas de 2000 já trazia os elementos que se intensificaram nos pós-atentados: "ao contrário do que em geral se afirma, não foram os indefensáveis atentados de 11/09 que mudaram o mundo, mas a ascensão de Bush e seus mentores ao governo dos Estados Unidos." (MARTINS, 2003, p. 31). A reação unilateral dos Estados Unidos se fortaleceu com os eventos de 11 de setembro, mas já estava anunciada desde o principio do governo Bush. Os atentados, de certo modo, forçam sua administração à necessidade de formular outro modo de se relacionar com seus aliados e demais parceiros no plano internacional. Porém, poucos meses depois do mundo prestar solidariedade aos Estados Unidos, a insistência nas políticas unilaterais do governo Bush solapou grande parte do apoio conquistado até então. E colocou novas variáveis no debate sobre a fisionomia da ordem internacional pós-guerra fria.

Superada a discussão sobre o declínio da hegemonia norte-americana dos anos 1980, a unipolaridade estratégica dos Estados Unidos recebeu destaque no debate das relações internacionais desde o início da transição geopolítica do sistema internacional, no começo dos anos 1990.

Do ponto de vista filosófico, a discussão acerca da formação de uma "nova" ordem internacional estava assentada nos valores do liberalismo. Assim, ela nos conduziria a um mundo mais integrado e cooperativo, embalando, ainda 
que momentaneamente, a ideia de redistribuição do poder entre as nações e uma suposta convergência de interesses entre elas (LAFER; FONSECA JUNIOR, 1994). No entanto, durou pouco esse otimismo liberal frente às mudanças sistêmicas iniciadas com o colapso inesperado da ordem da Guerra-Fria (1947-1989).

Decantado ao longo da década de 1990, o debate sobre a ordem internacional se deslocou do otimismo liberal na primeira parte dos anos noventa para um cenário mais pessimista. Nessa virada, conforme argumenta Fiori (1999), os Estados Unidos passam a perseguir e tentam impor uma nova hierarquia no sistema internacional, na qual eles figuravam como o juiz das relações internacionais. Para o autor, no campo geopolítico, já teríamos fortes indícios para caracterizar o cenário internacional dominado pela unipolaridade de Washington. Essa nova ordem não mais se baseia, segundo o autor, "no equilíbrio de poder, mas na capacidade de arbítrio militar e monetário da única superpotência mundial que sobreviveu à Guerra Fria e vem gerindo o mundo, de forma unipolar, desde 1991." (FIORI, 1999, p. 73).

Contudo, esta concepção de uma ordem unipolar em formação encontra discordâncias mesmo entre os mais severos críticos da hegemonia dos Estados Unidos no mundo contemporâneo. Para o embaixador Guimarães (2006), a liderança estratégica dos Estados Unidos no sistema internacional não implica que uma ordem de outra natureza não seja possível ou não esteja no horizonte das relações internacionais. Ainda que tenha imposto obstáculos ao desenvolvimento de uma ordem internacional de tipo diferente, é possível que, a partir da formação de novas coalizões, países intermediários como o Brasil e demais pólos emergentes de poder, atuem na busca de um equilíbrio maior no sistema internacional (CRUZ, 2007).

Em linhas gerais, o unilateralismo da Doutrina Bush (2002) ao atacar o multilateralismo e as instituições nas que se busca exercê-lo, desacreditava da hipótese de uma ordem internacional multipolar. A cisão, no seio da União Europeia, quando França e Alemanha cerram fileira contra o uso da força no Iraque e se opuseram frontalmente à estratégia dos Estados Unidos, demonstrava 0 desgaste entre seus aliados europeus da opção pela guerra como meio de resolução de conflitos. 0 Brasil somou-se aos países que defendiam uma saída diplomática e via Nações Unidas. 0 poder duro dava a tônica da política externa de Bush Jr. e a busca da supremacia era sua meta maior ao invés de uma hegemonia global com ares de Estado cosmopolita e baseado no soft power. 
0 emprego da noção de soft power (poder brando) para analisar as ações dos Estados Unidos nas relações internacionais foi cunhado por Joseph Nye Jr. ainda no final dos anos 1980. 0 autor, secretário-adjunto da Defesa no governo Clinton, define como poder brando a habilidade de um ator para persuadir outros a fazer 0 que ele deseja sem o emprego da força ou coerção, ou seja, sem recorrer ao poder bruto (hard power). Na década seguinte, Nye Junior (2002; 2004) desenvolveu com mais precisão seu conceito de poder brando, num contexto internacional de profundas transformações e no qual os Estados Unidos já figuravam na condição de única superpotência global.

A análise conceitual de Nye Junior (2002, p. 21) desenvolve-se à luz da hegemonia norte-americana e no modo como ela vai prosseguir no século XXI. Na introdução de seu livro o Paradoxo do poder americano, o leitor se depara com a seguinte indagação acerca do papel dos Estados Unidos na geopolítica mundial: "seremos capazes de utilizar sabiamente a nossa liderança, neste começo de século, para construir um arcabouço a longo prazo?"

Porém, essa convicção não estava clara em meados da década de 1970, quando teve lugar o debate acerca do declínio do poderio americano. Como um dos debatedores Nye Junior, juntamente com Robert Keohane, formulou 0 conceito de interdependência complexa como contraponto às teses defendidas por autores realistas no tocante à compreensão do papel dos Estados Unidos na ordem internacional. Nos primeiros anos da década de 1970, o prestigio e a liderança internacionais de Washington foram fortemente abalados pela crise do petróleo, pela derrota na guerra do Vietnã, pelo fim do padrão ouro-dólar, entre outros.

Em linhas gerais, o poder brando nos remete a um ambiente internacional no qual o multilateralismo, a cooperação e as instituições liberais são predominantes na vertente do internacionalismo liberal. Por outro lado, ainda que 0 autor ressalve que os dois sejam complementares, podemos entender o poder bruto como um cenário mais caracterizado pelos traços do realismo político, ou seja, pelo uso da força no lugar da diplomacia, do conflito e de um ambiente mais hostil ao poderio dos Estados Unidos.

Assim, para Nye, dado que a força não resolve todos os conflitos, há outras maneiras de um dado ator (A) influir no comportamento de outro(s) (B, C...) para levá-lo(s) a agir (em) de modo a satisfazer (em) os interesses de A. Essa concepção de poder é exercida de modo indireto. Segundo o autor, "na política mundial, é possível que um país obtenha os resultados que quer porque os outros desejam 
acompanhá-lo, admirando os seus valores, imitando-lhe o exemplo, aspirando ao seu nível de prosperidade e liberdade." (NYE JUNIOR, 2002, p. 36). 0 poder brando, de acordo com ele, pretende "levar os outros a querer o que você quer [...]. Ele coopta as pessoas em vez de coagi-las." (NYE JUNIOR, 2004, p. 36).

Outros componentes do poder brando, tão importantes quanto a cooptação, são a atração do modo de vida - no caso dos Estados Unidos - exercida sobre terceiros e a admiração que as instituições dos Estados Unidos despertam. 0 poder brando "não é simplesmente sinônimo de influência, embora seja uma fonte de influência. [...] 0 poder brando é mais que persuasão ou que a capacidade de mover as pessoas pela argumentação. É a capacidade de seduzir e atrair" (NYE JUNIOR, 2002, p. 37).

Essa maneira de operacionalizar a categoria poder subdividindo-a em duas dimensões considera as características intangíveis do poder por permitir incluir e dar mais relevo à cultura, à ideologia e aos valores supostamente mais fortes no poder de atração da sociedade norte-americana, facilitando com isso a difusão de seus valores, visão de mundo, estilos de vida e interesses por meio de sua política externa. 0 pano de fundo no qual o autor elabora sua análise é o da globalização econômica e informacional. E de certo modo guarda alguma relação com 0 conceito de hegemonia de inspiração crítica, ainda que não o reivindique ou se filie a essa perspectiva.

Contudo, conforme Ayerbe (2006), não se trata de concepções antagônicas - poder brando ou duro - quando se analisa a atuação internacional dos Estados Unidos seja em um governo republicano ou democrata. Para o autor:

A atuação internacional dos Estados Unidos tem uma dimensão essencialmente estrutural. As diferenças entre unilateralismo republicano e o multilateralismo democrata, entre os defensores do poder brando e os do poder duro, as abordagens cosmopolitas, imperiais ou nacionais, realistas, liberais ou institucionais referem-se mais aos meios que os fins da política externa (AYERBE, 2006, p. 77).

\section{O Brasil E O SISTEMA INTERNACIONAL APÓS 11 DE}

\section{SETEMBRO}

o lugar do Brasil neste novo ordenamento, mais competitivo e hierárquico, parece não ter recebido uma crítica mais aguçada da diplomacia brasileira. Desde 
a ascensão do governo Collor de Mello (1990-1992), a política externa brasileira padecia de ajustes e mudanças frente ao novo cenário internacional. A orientação calcada nos pressupostos do neoliberalismo refletiu fortemente na inserção subordinada do Brasil. A queda de Collor abriu um breve período de interregno da hegemonia neoliberal na política externa, momento em que Celso Amorim assumiu a pasta das Relações Exteriores, na administração Itamar Franco (1993-94).

Durante a primeira gestão de Cardoso (1995-1998) muitos desses pressupostos se faziam presentes, ainda que assumissem ares de modernidade. Como Ministro das Relações Exteriores, Fernando Henrique Cardoso, ao discorrer sobre a "profunda mudança no cenário internacional" e retomar o histórico da política externa do Brasil, indicava os desafios: "o novo quadro criado com o fim da guerra fria desafia a diplomacia brasileira a buscar outro tipo de inserção". A ênfase na diplomacia comercial se acentuou nos dois governos de Fernando Henrique Cardoso (1995-2002).

Em um cenário marcado pela arbitrariedade e acirramento da vontade hegemônica dos Estados Unidos, a política externa brasileira apostou timidamente na multipolaridade emergente. No entanto, os atentados e toda sua violência deixaram ainda mais a margem a América Latina. Na administração de Fernando Henrique Cardoso (1995-2002), marcada pela diplomacia presidencial, a inserção internacional do Brasil guiou-se pelos princípios do otimismo liberal. Deveríamos extrair desse novo período da história mundial, com habilidade e competência, o máximo de oportunidades e realizações (LAFER; FONSECA JUNIOR, 1994).

Ainda que o Brasil não tenha adotado o "realismo periférico", que propõe uma atitude subserviente e adesista à potência dominante, e nem almejado "relações carnais", conforme expressou um dos ministros das Relações Exteriores do governo de Carlos S. Menem, as relações com os Estados Unidos foram pautadas pela cordialidade e não confrontação. A ênfase estava na "autonomia pela participação", caracterizada pela busca de credibilidade.

A vertente da credibilidade se orienta pela visão liberal das relações internacionais. Essa concepção, de acordo com Guimarães (2006, p. 55-56),

Considera que o sistema internacional é formado por Estados iguais, de poder semelhante, que tendem a cooperar entre si para 0 bem-estar da humanidade e a paz. [...] 0 ideal para a inserção política do Brasil no mundo é cooperar com todos os Estados, se antecipar nos processo de paz e desarmamento, não desafiar as grandes potências [...] não procurar exercer qualquer 
protagonismo em razão da escassez de poder do Brasil e aceitar as regras do sistema internacional.

0 comportamento esperado "dos países periféricos colaborativos", segundo Guimarães, é o de sempre se submeterem aos interesses do hegemon. Na véspera dos atentados, os ministros das relações exteriores dos países membros da Organização dos Estados Americanos encontravam-se reunidos em Lima (Peru). Em função da gravidade dos acontecimentos, o fim dos trabalhos fora antecipado. 0 então chanceler brasileiro Celso Lafer propôs que o Tratado Interamericano de Ajuda Mútua e Recíproca (TIAR) de 1947, e praticamente enterrado na Guerra das Malvinas (1982), quando os Estados Unidos ficaram ao lado da Grã-Bretanha, fosse utilizado para fazer frente aos terríveis acontecimentos nos Estados Unidos. Isso causou certo estranhamento e desconforto entre os países da região.

Um ano antes, na Reunião de Brasília (2000), o governo Cardoso dava sinais de retomar "um discurso diplomático autonomista (ainda que não confrontacionista) por parte do Brasil, que critica a 'globalização assimétrica" (VIZENTINI, 2008, p. 99). A crise no Mercosul e a desvalorização do Real, em 1999, somados aos avanços da agenda de negociações para a formação da Área de Livre Comércio das Américas foram as principais razões dessa iniciativa da diplomacia brasileira à época. A iniciativa do presidente tinha como objetivo resgatar o conceito de América do Sul ensaiado pelo projeto da ALCSA em 1993. No final da gestão Cardoso, a diplomacia brasileira passou a conceber um novo desenho geopolítico regional, pondo em marcha o conceito de América do Sul e que será aprofundado e dotado de um forte viés político na gestão Lula da Silva.

\section{O GOVERNo Lula E A ERA BuSH: INTERESSE NACIONAL E ORDEM MUNDIAL}

As relações do Brasil com os Estados Unidos no governo Lula da Silva se mantiveram dentro dos moldes da noção de "divergência limitada" e, como demonstra o histórico das relações bilaterais ao longo do século XX, continuam ocupando lugar crucial na política externa brasileira (LIMA; HIRST, 2006). Para um presidente eleito por um partido situado à esquerda no espectro ideológico e crítico histórico da atuação internacional dos Estados Unidos, a estratégia do Brasil de Lula da Silva foi a de estabelecer relações maduras com a hiperpotência. As relações com os Estados Unidos, segundo Guimarães (2006), orientaram-se por uma visão da realidade internacional calcada na defesa dos interesses nacionais e 
na recusa das hegemonias de todos os tipos, sem com isso adotar uma postura anti Estados Unidos. Para o autor:

As relações do Brasil com os Estados Unidos podem se revestir de enorme delicadeza, mas o princípio básico deve ser 0 de que 0 governo brasileiro não tem nenhuma razão para se submeter à hegemonia americana. Não tem 0 direito de exercer uma política de submissão, ainda que disfarçada, pois uma política externa independente, firme e serena não será punida nem econômica nem muito menos militarmente pelos Estados Unidos, que respeitam mais os Estados que se respeitam do que aqueles Estados que se submetem espontaneamente à sua hegemonia (GUIMARÃES, 2006, p. 267268).

De acordo com o então secretário-geral do MRE (2003-2009), uma atuação internacional orientada por uma nova estratégia diplomática implicava em abandonar os pressupostos da diplomacia da credibilidade em prol de outra, referenciada na concepção da diplomacia desenvolvimentista. Dado que uma política externa com credibilidade internacional e uma política externa independente não são excludentes.

Ao contrário da concepção liberal das relações internacionais, a percepção da vertente autonomista, com raízes no nacional-desenvolvimentismo, inscrito na formação diplomática do País desde meados do século XX e retomado em anos mais recentes, realça os aspectos da hierarquia internacional e a acirrada competição na ordem internacional contemporânea.

A vertente autonomista combina o objetivo de projeção internacional com a permanência do maior grau de flexibilidade, liberdade da política externa e diversificação nas relações externas. Nela, os resultados da liberalização comercial são vistos com reticência e a adesão aos regimes internacionais é encarada de modo crítico. No horizonte, essa vertente vislumbra influir no jogo de poder internacional por meio da elaboração de arranjos ou coalizões com Estados-nação de perfil aproximado ao seu (SOUZA, 2009).

Para a América Latina e, mais especificamente a América do Sul, a virada dos anos oitenta para os noventa representou a ocorrência de mudanças nos regimes políticos e a passagem da década não deixou para trás os efeitos da crise da dívida externa, arrastando as mazelas provocadas pela malfadada 'década perdida' e seu pífio crescimento econômico. 0 retorno de governos eleitos democraticamente, principalmente nas maiores economias da região, entre as quais o Brasil, coincidiu 
com a adoção das políticas neoliberais: desregulamentação da economia, abertura econômica, privatizações entre outras - também conhecidas como Consenso de Washington, dominaram a vida política nacional e varreram a América Latina. Com graus diferenciados de adesão dos países da região a essa plataforma, supostamente modernizadora, foi apresentada como redentora dos graves problemas econômicos, sociais, políticos e do desenvolvimento da América Latina (FIORI, 1999). Desde a eleição de Hugo Chávez em 1999 na Venezuela, fruto do descontentamento com o projeto neoliberal, nos anos seguintes forças políticas oriundas de um amplo espectro de esquerda assumiram o poder no Brasil, no Equador, na Bolívia entre outros.

No governo Lula da Silva, no plano global, as prioridades foram 0 multilateralismo (reforma do processo decisório da ONU, não-proliferação), o desenvolvimento de uma política comercial mais afirmativa com atuação nos diversos tabuleiros (o da OMC, o da ALCA, o das negociações Mercosul-União Européia), parcerias diversificadas no âmbito "Sul-Sul" com países semiperiféricos grandes (África do Sul, China, Índia), além de Rússia.

Anova estratégia da política externa brasileira não trazia em si o entusiasmo pela formação da ALCA, o que não implicou pura e simplesmente o abandono das negociações. Somadas às dificuldades do governo norte-americano em relação aos subsídios agrícolas e o redirecionamento de sua política externa para a questão da segurança e a luta contra o terrorismo. Esse "desinteresse" por parte dos Estados Unidos associado à resistência brasileira acabou por contribuir decisivamente pela inviabilização das negociações.

A posição brasileira passou a reforçar em seus discursos e propostas o fato de que o "livre comércio" representado pela ALCA ia além das regras negociadas na $\mathrm{OMC}$, e esse escopo amplo da iniciativa representava uma das principais dificuldades para se chegar a um acordo final. Cobrindo nove grandes áreas, a ALCA implicava na capacidade reguladora em temas chaves para o desenvolvimento brasileiro como política industrial, de concorrência e propriedade intelectual, entre outras. Os prazos eram outro complicador para o novo governo.

Empossado em 2003, o governo Lula da Silva tinha poucos meses para apresentar suas ofertas para cada uma das áreas implicadas no processo negociador. Em meio à troca da equipe à frente das negociações e diante de um contexto negociador complexo e de um calendário que, segundo Amorim, deixava escassa margem para uma eventual correção de rumos, o Itamaraty reorientou a 
estratégia brasileira. 0 projeto, tal como se encontrava, embutia uma concepção de livre comércio abrangente, abarcando aspectos normativos que incidiam sobre a capacidade reguladora dos países (AMORIM, 2003).

A avaliação da nova política externa do processo negociador era a de que tal como vinha sendo trabalhada ela não interessava ao Brasil. No entanto, a aversão do governo Lula da Silva à ALCA e sua avaliação de que se tratava de um projeto hegemônico dos Estados Unidos, que poderia representar uma anexação da região à economia deles, não levou a um abandono das negociações. Pelo contrário, a estratégia brasileira que desagradou tanto Washington como os seus aliados chaves (Canadá, México e Chile) se beneficiou da perda de importância do tema na gestão Bush e do novo cenário político da América Latina.

Em meio ao clima de impasse nas negociações da VIII Reunião Ministerial da ALCA em Miami (2003), os países acordaram novas bases para as negociações deixando de lado a proposta de uma ALCA "abrangente". Tido como ambicioso e inviável em sua versão original pelo Brasil.

0 fracasso da Cúpula de Miami praticamente enterrou as negociações da ALCA e representou uma vitória das nações que a todo custo resistiam a sua conclusão tal como vinha sendo negociada. Na Cúpula de Mar del Plata (2005) ela seria finalmente rejeitada pela Venezuela, Brasil e demais países do Mercosul, e assim aos poucos saiu da agenda principal do País.

Ela não foi assinada porque não atendia 0 interesse nacional. Não tem nada de ideologia quando muito pode ser o molho do filé, mas o filé era esse. Não correspondia ao interesse nacional e pelo contrário, seria extremamente prejudicial para o interesse nacional. Em segundo lugar nós também tínhamos a intenção de transferir algumas das questões que poderiam interessar na ALCA para a Rodada de Doha. Conseguimos avançar muito e depois tivemos a frustração dela. Parece-me de certa maneira o lugar onde nos temos mais possibilidades de acumular força porque do que na negociação com a America. É importante dizer que o Mercosul ali se comportou bonito e em realidade quem derrubou a ALCA foi a articulação do Brasil com a Argentina e 0 acordo que o Uruguai e Paraguai tiveram e a Venezuela. 0 Chávez acha que as mobilizações que houve em Mar del Plata derrubaram a ALCA. Mas ali foi muito mais correr para o abraço, porque o gol já tinha sido feito lá atrás, o gol foi feito na sala de reuniões. Foi um momento muito importante do ponto de vista de um afiançamento das relações da Argentina com o Brasil. A Alca Não interessava para o País. (GARCIA, 2009). 
Sem desistir do seu projeto estratégico de integrar as economias da região a partir de seus interesses econômicos, políticos e comerciais, os Estados Unidos voltaram-se para a elaboração de acordos bilaterais com o Chile (2003), Peru (2005), Colômbia (2006) e CAFTA-R (2006)².

\section{Considerações FINAIS}

Dez anos após os atentados de 11/09, os Estados Unidos sentem que a ordem internacional trouxe novos desafios para a sua posição de país líder. 0 unilateralismo da Doutrina Bush cedeu espaço lentamente para a retomada da agenda multilateral de Barack Obama, embora o fracasso retumbante no Iraque tenha se estendido até 2011. A emergência de novos pólos de poder, destacadamente a China, com sua pujança econômica e taxas elevadas de crescimento do seu PIB representam um desafio imenso no médio prazo.

Juntamente com China, Índia, Rússia e África do Sul, o Brasil reúne-se no fórum Brics. 0 papel da China e dos novos pólos de poder na ordem internacional mudou substancialmente, e o caminho da multipolaridade ganhou mais força. Já não parecem possíveis ações unilaterais dos Estados Unidos sem o consentimento ou apoio dos antigos aliados e dos novos atores internacionais.

No governo Lula da Silva, o Brasil valorizou mais enfaticamente a formação de coalizões no eixo "Sul-Sul", como meio de diminuir as assimetrias de poder presentes nas relações internacionais contemporâneas. Com as parcerias estratégicas ou laços mais estreitos com Índia, África do Sul, China e Rússia, o País ganhou mais evidência no cenário internacional. Na era dos gigantes o estreitamento das relações Sul-Sul figura como uma das possibilidades de reduzir assimetrias das "estruturas hegemônicas de poder" e se torna um exercício criativo para um País do porte do Brasil na construção de alternativas. As estruturas de poder não são estáticas nem fechadas em si mesmas. Por essa razão, é preciso localizar e aproveitar as "brechas no meio internacional para relacionamentos construtivos e autônomos em relação à agenda internacional que refletem as perspectivas de Washington" (ALMEIDA FILHO, 2009, p. 80).

Nesse contexto, o Fórum de Diálogo Índia, Brasil e África do Sul (IBAS) instituído pela Declaração de Brasília (junho de 2003), apenas três meses após a Guerra do Iraque, abarca um extenso programa de cooperação. Na perspectiva da política externa brasileira, a instituição de coalizões do tipo IBAS contribui para

${ }^{2}$ Central América United States Free Trade Agreement. 
uma ordem internacional multipolar. Os três integrantes partilham de algumas características em comum: situam-se na periferia do capitalismo ("países intermediários"); possuem economias dinâmicas e exercem papel de relevo em suas respectivas regiões. Mesmo não apresentando comportamento uniforme perante aos desafios no sistema internacional, esse mecanismo de associação em coalizão busca abrir novos espaços de atuação para os seus integrantes.

A noção de soft Power, apesar de sugerir uma dominação (no sentido weberiano de consentimento), quando transposta para o plano internacional assume a imagem do brilho da espada, uma das feições da espada. No fundo, os termos soft ou hard se referem mais aos meios que aos fins da política externa dos Estados Unidos. 0 11/09 assinalou uma mudança não tanto da parte dos Estados Unidos perante as relações internacionais, mas sim uma transformação da conjuntura internacional que desafia a suposta condição imperial de Washington. Como bem anotou Hobsbawm (2000): "uma coisa me parece cada vez mais evidente: 0 mundo tornou-se grande e complexo demais para ser dominado por um único Estado... Enquanto historiador, considero equivocada a ideia de que uma potência única, por maior e mais poderosa que seja, possa assumir o controle da política mundial" (HOBSBAWN, 2000, p. 56-57). A crise econômica internacional debilitou ainda mais essa possibilidade.

\section{REFERÊNCIAS}

ALMEIDA FILHO, João Genésio. O fórum de diálogo Índia, Brasil e África do Sul (IBAS): análise e perspectivas. Brasília: FUNAG, 2009.

AMORIM, Celso. A ALCA possível. Folha de São Paulo, São Paulo, 8 jun. 2003.

ASH, Timothy Garton. Onze de setembro. Folha de São Paulo, São Paulo, 15 set. 2001.

AYERBE, Luiz Fernando. 0 poder estadunidense. In: Ordem, poder e conflito. São Paulo: Unesp, 2006. p. 15-78.

BERNAL-MEZA, Raul. Multilateralismo e unilateralismo na política mundial: América Latina frente à ordem mundial em transição. Revista Brasileira de Política Internacional, Brasília, v. 48, n. 1, p. 5-23, 2005.

BRAUDEL, Fernand. A longa duração. In: História e ciências sociais. Lisboa: Presença, 1972. p. 7-70. 
CRUZ, Sebastião C. Velasco. Reestruturação econômica mundial, mudança geopolítica e reformas nos países periféricos. In: .Trajetórias: capitalismo neoliberal e reformas econômicas nos países da periferia. São Paulo: Unesp, 2007. p. 389-409.

FIORI, José Luis. Prefácio. In: O poder global e a geopolitica das nações. São Paulo: Boitempo, 2007. p. 13-40.

. (Org.). Estados e moedas no desenvolvimento das nações. Petrópolis: Vozes, 1999.

GARCIA, Marco Aurélio. Entrevista ao autor. Brasília, 2009.

GUIMARÃES, Samuel Pinheiro. Desafios brasileiros na era dos gigantes. Rio de Janeiro: Contraponto, 2006.

HOBSBAWM, Eric. Para onde vai o império americano? O Estado de S. Paulo, São Paulo, 29 jun. 2003. p. A-20-21.

. O novo século. São Paulo: Cia. das Letras, 2000. . Ecos da Marselhesa. São Paulo: Cia das Letras, 1990.

LAFER, Celso; FONSECA JUNIOR, Gelson. Questões para a diplomacia no contexto internacional das polaridades indefinidas (notas analíticas e algumas sugestões). In: FONSECA JUNIOR, G.; CASTRO, S. H. N. (Org.). Temas de politica externa brasileira II. São Paulo: Paz e Terra, 1994. p. 49-77. v. 1.

LIMA, Maria R. Soares; HIRST, Mônica. Brazil as an intermediate state and regional power: action, choice and responsabilites. International Affairs, Guildford, v. 82, n. 1, p. 21-40, 2006.

MARTINS, Luciano. 0 fundamentalismo de Bush e a nova ordem mundial. Política Externa, São Paulo, v. 12, n. 1, p. 31-42, jun./ago. 2003.

NYE JUNIOR, Joseph. Soft power: the means to success in word politics. Nova York: Public Affairs, 2004.

. O paradoxo do poder americano. São Paulo: Unesp, 2002.

SOUZA, Amaury de. A agenda internacional do Brasil. Rio de Janeiro: Campus, 2009 .

VIZENTINI, Paulo Fagundes. 0 Brasil, o Mercosul e a integração da América do Sul. In: WIESEBRON, M. e GRIFFITHS, R. (orgs.). Processos de integração regional e cooperação intercontinental desde 1989. Porto Alegre: Ed. UFRGS, 2008, pp. 93-108. 